\title{
Erratum
}

\section{School-based Prevention of Bullying and Relational Aggression: The fairplayer.manual}

Heike Dele Bull, Martin Schultze and Herbert Scheithauer

[International Journal of Developmental Science, 3, 2009, 312-317. DOI: 10.3233/DEV-2009-3310]

In the article by Bull, Schultze, and Scheithauer (2009) the following error occurred on page 313:

"43 students attended the long term intervention $\left(\mathrm{IG}_{\text {long }}, 10\right.$ weeks of treatment.manual participation."

Correct is:

"43 students attended the long term intervention $\left(\mathrm{IG}_{\text {long }}, 16\right.$ weeks of treatment participation)".

The authors regret having not detected this error earlier. 